\title{
AVALIANDO A CONTAMINAÇÃO POR ELEMENTOS TRAÇO EM ATIVIDADES DE MARICULTURA. RESULTADOS PARCIAIS DE UM ESTUDO DE CASO REALIZADO NA ILHA DE SANTA CATARINA, BRASIL
}

\author{
Adilson J. Curtius, Edson L. Seibert e Haidi D. Fiedler* \\ Departamento de Química, Universidade Federal de Santa Catarina, CP 476, 88040-900 Florianópolis - SC \\ Jaime F. Ferreira \\ Departamento de Aqüicultura, Universidade Federal de Santa Catarina, CP 476, 88040-900 Florianópolis - SC \\ Paulo H. F. Vieira \\ Departamento de Sociologia e Ciência Política, Universidade Federal de Santa Catarina, CP 476, 88040-900 Florianópolis - SC
}

Recebido em 1/3/02; aceito em 11/6/02

\begin{abstract}
EVALUATING TRACE ELEMENT CONTAMINATION IN MARICULTURE ACTIVITIES. PARTIAL RESULTS OF A CASE STUDY CARRIED OUT IN THE COASTAL REGION OF SANTA CATARINA, BRAZIL. Adopting the perspective of human health risk assessment, an interdisciplinary research group has been investigating since 1998 the quality of mussels and oysters cultivated in coastal zones of Santa Catarina State. Evaluation of physico-chemical parameters considered relevant in measuring the degree of eutrophication showed values compatible with the dynamics of well balanced environmental systems. Concentrations of metallic and semi-metallic elements in seawater and bivalves were found to be similar to or lower than those found in Chile, Greenland and the USA. Further investigations focusing upon sediments will provide new and useful data for the management of sustainable mariculture strategies in Brazil.
\end{abstract}

Keywords: quality assurance; mariculture development; risk assessment.

\section{INTRODUÇÃO}

A maricultura constitui atualmente um dos setores produtivos mais dinâmicos do Estado de Santa Catarina. O cultivo de mexilhões, por exemplo, foi introduzido em 1989 com base em pesquisas experimentais realizadas pela Universidade Federal de Santa Catarina e pela Associação de Crédito e Assistência Pesqueira de Santa Catarina (ACARPESC, atualmente EPAGRI S/A). A espécie cultivada - Perna perna - é considerada o maior mitilídio brasileiro, podendo ser encontrado em abundância na orla litorânea que se estende do Estado do Espírito Santo ao de Santa Catarina ${ }^{1-2}$. Segundo Roczanski et al. ${ }^{1}$, a safra obtida com cultivos desta espécie em 1999 chegou a alcançar um patamar de 9.460 toneladas.

Da mesma forma, vêm se intensificando rapidamente as atividades de ostreicultura, através do cultivo da ostra-do-pacífico (Crassostrea gigas), utilizando-se para tanto sementes produzidas no Laboratório de Cultivo de Moluscos Marinhos da UFSC. Esta espécie de ostra passou a ser muito utilizada no Brasil, em função do seu rápido crescimento. Além disso, experiências promissoras com a ostra-do-mangue, ou nativa (Crassostrea rhizophorae), encontramse em estágio experimental. Vale a pena ressaltar ainda que a expansão mais representativa da produção de ostras ocorreu no período 1999/2000, concentrando-se principalmente no município de Florianópolis. Na última safra, este município contribuiu com 83,3\% do volume total de ostras produzidas no conjunto do Estado de Santa Catarina, considerado hoje em dia o maior produtor de organismos aquáticos cultivados do país ${ }^{1,2}$.

Todavia, apesar do inegável potencial socioeconômico contido nestas experiências, o atual padrão de desenvolvimento acelerado e intensivo das práticas de maricultura no Estado não está isento de riscos. Possíveis impactos destrutivos do ponto de vista da pesquisa socioambiental incluem, entre outros, distúrbios das comunidades

*e-mail: fiedler@qmc.ufsc.br naturais de fitoplâncton, deposição de matéria orgânica no fundo das áreas de cultivo, contaminação genética de estoques selvagens, introdução de espécies que competem com as já existentes e disseminam doenças nos estoques naturais e, finalmente, ameaças à saúde pública pelo fato dos cultivos serem realizados na ausência de um sistema realmente eficaz de monitoramento da qualidade das águas e dos produtos cultivados. Este último aspecto tem sido colocado em primeiro plano nos debates sobre políticas de fomento às atividades de maricultura no Estado, onde começa a ser melhor percebida a magnitude dos riscos gerados pela presença de metais e semi-metais, substâncias químicas e bactérias.

Atualmente, as perspectivas de exportação dos cultivos para outros Estados permanecem dependentes da emissão de um Certificado de Inspeção Federal (CIF). No caso da exportação para os mercados europeu, norte-americano e japonês (NAFTA, Mercado Asiático e Mercado Comum Europeu), envolvendo países que têm enfrentado sérios problemas de contaminação por metais e semi-metais nas últimas décadas, exige-se, através da indicação dos níveis destes elementos nos produtos exportados, que os parâmetros de qualidade analítica indicados nos rótulos sejam rigorosamente atendidos ${ }^{3}$.

Em conseqüência, vem se impondo pouco a pouco a necessidade de se fazer frente a este novo contexto de intercâmbios comerciais através de estudos especializados, com perfis inter e transdisciplinar. No caso das avaliações de elementos traço, uma operação que requer instrumentação analítica moderna e controle de qualidade sofisticado, a consolidação e disseminação deste tipo de pesquisa vem sendo considerada de importância fundamental para que profissionais das áreas de Química, Aqüicultura, Bioquímica, Geociências e Ciências Sociais, em parceria com representantes de empresas governamentais e privadas e agentes do setor público possam convergir na criação de novos instrumentos jurídicos e arranjos institucionais capazes de minimizar os riscos socioambientais das práticas de maricultura no futuro e favorecer, no presente, o atendimento de uma demanda crescente por produtos dispondo de certificação de qualidade. 
Como se sabe, o Brasil continua a adotar como padrão de referência para fins de certificação a Resolução CONAMA nº 20 de 1986, inserida na Lei ${ }^{\circ} 9.433$, de 8 de janeiro de 1997. Esta última institui a Política Nacional de Recursos Hídricos e cria o Sistema Nacional de Gerenciamento de Recursos Hídricos, mas responde apenas pela normatização dos níveis de metais totais ${ }^{4}$. A percepção de suas limitações face à nova realidade imposta pela globalização dos circuitos econômicos e culturais vem se tornando cada vez mais nítida tanto no ambiente acadêmico quanto na órbita empresarial.

Neste sentido, seria importante ressaltar que em países mundialmente reconhecidos pelo seu dinamismo na gestão do setor de maricultura, os níveis aceitáveis de micropoluentes no meio natural são fixados de maneira rigorosa. Além da especificação de espécies químicas para os elementos de maior toxicidade, constata-se que os níveis tolerados são bem inferiores àqueles permitidos pela legislação em vigor no Brasil ${ }^{5-7}$. Esta constatação torna-se relevante se levarmos em conta que uma concentração elevada de excrementos de moluscos no fundo do mar pode vir a transformar as espécies químicas geralmente encontradas nos ecossistemas costeiros e, eventualmente, desencadear processos de eutrofização devido à degradação sinergística do meio. Um exemplo expressivo desta espécie de dano socioambiental está representado na literatura técnica sobre a Baía de Chesapeake ${ }^{8}$, onde as causas da dinâmica de degradação ecossistêmica foram correlacionadas tanto à poluição induzida por nutrientes quanto à superexploração de ostras nativas através de coleta mecânica.

Por outro lado, devido à sua capacidade de bioconcentrar metais traço e compostos orgânicos, certos organismos aquáticos vêm sendo utilizados nos últimos anos no monitoramento da poluição em ambientes costeiros. Concentrações de contaminantes em tecidos de mexilhões e ostras dependem certamente do nível de desenvolvimento do organismo, da salinidade e da temperatura do meio e do estágio de reprodução já alcançado. Constituem portanto bons indicadores de biodisponibilidade ${ }^{9-14}$.

A poluição por metais pesados está associada, por um lado, a metais presentes na forma dissolvida, ou com matéria particulada em suspensão na coluna de água; por outro, ao plâncton, pelo fato dos metais ingeridos pelos moluscos acumularem-se preferencialmente nos tecidos viscerais ${ }^{14,15}$. Torna-se assim importante conhecer a quantidade de metal na forma livre iônica dissolvida que é, freqüentemente, muito menor do que o conteúdo total ${ }^{16,17}$. De acordo com Allen e Hansen ${ }^{16}$, a biodisponibilidade de um metal e, conseqüentemente, sua toxicidade dependem da forma química e física na qual o metal se encontra. De fato, todos os equilíbrios possíveis com os diferentes ligantes presentes devem ser considerados, sendo que a ligação de, por exemplo, cobre à matéria orgânica dissolvida ou a material particulado pode diminuir sua biodisponibilidade ${ }^{16}$. Tratase, portanto, de um problema extremamente complexo onde tanto o equilíbrio, quanto a cinética dos diferentes processos de adsorção, complexação dos diferentes processos que podem acontecer devem ser considerados ${ }^{18}$. Mesmo que estes valores sejam considerados baixos - em elementos traço são levados em conta níveis de ppm - os impactos do ponto de vista ecotoxicológico podem alcançar proporções surpreendentes ${ }^{16,18}$.

Em geral, espécies dissolvidas são aquelas que, por definição, passam através de uma membrana filtrante de tamanho nominal $<0,45 \mu \mathrm{m}$, na qual o material particulado é retido. Desta forma os resultados de elementos químicos são analisados como presentes na forma de espécies dissolvidas ou particuladas ${ }^{19}$.

As atividades antrópicas figuram no rol das mais importantes entradas de elementos traço tóxicos em águas, sedimentos e biota ${ }^{20}$. Elevadas concentrações de $\mathrm{Cd}, \mathrm{Hg}, \mathrm{Pb}$, e $\mathrm{Sn}$ e semi-metais, como As, poderão produzir efeitos nocivos sobre os próprios organismos aquáticos ou seus predadores, uma vez que estes são biomagnificados na cadeia trófica ${ }^{21}$.
Analiticamente, devido à capacidade de análise multielementar, alta sensibilidade e medida da razão isotópica, o uso da espectrometria de massa com fonte de plasma indutivamente acoplado (ICP-MS) ${ }^{22}$ torna-se vantajosa para a solução de problemas encontrados em materiais biológicos de ambientes marinhos, no contexto de pesquisas voltadas à abertura de novas opções de gestão integrada e descentralizada de atividades de maricultura ${ }^{23}$.

A determinação de elementos traço em água do mar torna-se problemática pelo fato de existirem concentrações elevadas de elementos da matriz ${ }^{24}$ (aproximadamente 0,5 $\mathrm{M}$ de $\mathrm{NaCl}$ ), e uma baixíssima concentração de elementos traço ${ }^{25}$. Quando se utiliza ICPMS, a determinação direta é problemática, devido ao alto teor de sólidos encontrado na matriz (em torno de $3 \% \mathrm{~m} / \mathrm{v}$, enquanto que o espectrômetro tolera no máximo $0,2 \%$ ) e também às interferências causadas por íons poliatômicos provenientes de elementos como $\mathrm{Ca}$, $\mathrm{Cl}$, Na e S. Além disso, existem riscos de supressão da ionização, em função das concentrações maciças de elementos alcalinos.

Na pesquisa realizada em três zonas de cultivo na Ilha de Santa Catarina, ao longo dos meses de abril e outubro nos anos de 1999 e 2000, a qualidade das águas foi avaliada em termos da concentração de metais e semi-metais e da presença de certos parâmetros físicoquímicos julgados relevantes face à problemática da pesquisa. Por outro lado, a qualidade de mexilhões Perna perna e ostras Crassostrea gigas foi avaliada em termos da concentração de elementos traço. A determinação de metais e semi-metais foi empreendida usando-se a vaporização eletrotérmica (ETV) para a introdução de amostras no ICP-MS. Este acoplamento permite separar a maior parte da matriz antes da introdução do analito no plasma, possibilitando assim a análise direta da água do $\operatorname{mar}^{24}$.

Finalmente, seria importante ressaltar que este diagnóstico preliminar está inserido num programa de longo prazo de investigações comparativas, orientadas no sentido da avaliação permanente e da gestão integrada e participativa de riscos de contaminação nas práticas de maricultura desenvolvidas no litoral do Estado de Santa Catarina. A abordagem de avaliação de riscos à saúde humana foi considerada tributária de inovações metodológicas associadas aos campos emergentes de pesquisa inter e transdisciplinar sobre avaliação de impactos socioambientais e gestão comunitária de recursos naturais renováveis ${ }^{26-29}$.

Pressupondo-se que as dimensões do risco e da qualidade socioambiental deveriam ser descritas, sempre que possível, com a ajuda de indicadores construídos através de procedimentos compatíveis com a pesquisa empírica rigorosa, e apreendidas no nível de sua percepção pelos diferentes atores sociais envolvidos - implicando, dessa forma, o enfrentamento dos dilemas relacionados à fixação de margens de risco socialmente aceitáveis, em contextos marcados por incertezas científicas e controvérsias sociais, o roteiro metodológico "standard" para o desenvolvimento deste ambicioso programa de investigação inclui: (1) a identificação precisa do amplo espectro de riscos associados à maricultura; (2) a busca de caracterização precisa dos mesmos, incluindo-se a identificação de suas causas estruturais e das tendências prováveis de agravamento progressivo dos mesmos; (3) a delimitação das margens socialmente aceitáveis de risco em cada contexto socioecológico, envolvendo estudos de percepção e de atitudes dos diferentes atores sociais face aos riscos atuais e potenciais de projetos e programas de maricultura, as modalidades usuais de regulamentação jurídica de danos socioambientais e as disfunções dos sistemas de gestão ambiental instituídos; e finalmente (4) a oferta de subsídios visando consolidar e aperfeiçoar as instituições voltadas à gestão democrática dos riscos identificados, envolvendo-se o desenho de opções alternativas de controle de qualidade dos produtos e a definição de critérios para o monitoramento permanente dos processos produtivos, tendo em vista a minimização dos riscos atuais e potenciais en- 
volvidos. Neste sentido, parte-se da premissa segundo a qual a busca de garantia da qualidade dos produtos cultivados realizada de um ponto de vista efetivamente preventivo e pró-ativo passa, em última instância, pela pesquisa de um novo paradigma de desenvolvimento regional e urbano ${ }^{28}$.

\section{PARTE EXPERIMENTAL}

\section{Amostragem}

O Laboratório de Cultivo de Moluscos Marinhos da UFSC foi responsável pela produção de sementes de ostras da espécie Crassostrea gigas, provenientes de três diferentes períodos de larvicultura em laboratório. Ao mesmo tempo, os pesquisadores associados assumiram os desafios ligados à coleta e seleção de sementes do mexilhão Perna perna, utilizando-se para tanto os coletores existentes na praia do Sambaqui.

As ostras de cada lote provinham da mesma larvicultura e tinham, na época da montagem do lote, entre 4,0 e $5,5 \mathrm{~cm}$. Por sua vez, o tamanho dos mexilhões oscilava entre 3,0 e 4,0 cm. Estas dimensões foram adotadas tendo em vista a necessidade de minimizar diferenças nas taxas de crescimento e de mortalidade, permitindo assim que os animais chegassem com segurança ao tamanho comercial no espaço de tempo de seis meses, entre o início do cultivo e a análise de cada lote. Além disso, os mexilhões foram mantidos em cordas específicas para este tipo de cultivo (feitas de polietileno e algodão), cujo comprimento oscilava entre 0,9 e 1,2 m, contendo cerca de 2,0 kg de sementes (aproximadamente 600 animais). Em cada local selecionado foram colocadas duas lanternas de ostras e três cordas de mexilhões, as quais permaneceram no mar por um período de seis meses. Durante este período, não foi preciso realizar qualquer tipo de manejo com os mexilhões. Quanto às ostras, foram submetidas a um regime semestral de manejo para limpeza das lanternas.

Na Figura 1 estão indicados os locais de cultivo, situados nas proximidades da Ilha de Santa Catarina, a saber: na Enseada da Pinheira, município de Palhoça, a 50 km de Florianópolis (cultivo realizado pela empresa Moluskus); na praia de Sambaqui (cultivo realizado pela Associação dos Miticultores do Norte da Ilha); e finalmente na praia do Ribeirão da Ilha (cultivo realizado pela Associação dos Miticultores do Sul da Ilha). As coletas de mexilhões e ostras, água do mar e sedimentos marinhos foram realizadas nos meses de abril e outubro dos anos de 1999 e 2000.

\section{Determinação de parâmetros físico-químicos da água do mar}

Para a determinação de temperatura, $\mathrm{pH}$, salinidade e oxigênio dissolvido (OD) foi utilizado um equipamento multiparâmetro Multiline P4 WTW, sendo que as determinações foram realizadas in loco. Os parâmetros relacionados a seguir foram determinados no laboratório, sendo que as amostras de água foram obtidas com o auxílio de uma garrafa "Nansen", a saber: i) determinações de turbidez usando um turbidímetro marca Lamote (modelo 2020); ii) matéria particulada total (MPT), matéria orgânica (MOP) e matéria inorgânica em suspensão (MIP) foram avaliados segundo a metodologia básica descrita em Strickland e Parsons ${ }^{30}$; iii) clorofila $\boldsymbol{a}$, foi determinada através do método fluorométrico ${ }^{30,31}$. Em todos os casos foram realizadas três medidas para cada local e dia de coleta.

\section{Instrumentação}

As determinações de metais e semi-metais foram realizadas num espectrômetro de massa com fonte de plasma indutivamente acoplado ELAN 6000 da Perkin-Elmer SCIEX (Thornhill, Toronto, Canada).
As condições de operação do espectrômetro foram sempre ajustadas após a realização de um teste, com o propósito de se obter a máxima produção de íons $\mathrm{M}^{+}$e mínima produção de sinal para $\mathrm{M}^{++}$, $\mathrm{MO}$, e fundo em $\mathrm{m} / \mathrm{z}$ 220. Nebulizador de fluxo cruzado; câmara de prémistura do tipo Scott e uma bomba peristáltica modelo Gilson foram usados para a nebulização pneumática. Também foi usado um vaporizador eletrotérmico HGA-600 MS, equipado com amostrador automático AS-60 da Perkin Elmer (Norwalk, USA) e usados tubos de grafite recobertos piroliticamente (Perkin Elmer, no 091 504).

\section{Preparação do material}

Todos os frascos para acondicionamento das amostras e soluções e os materiais de vidro foram mantidos em ácido nítrico $10 \%$ v/v por no mínimo 5 dias, ou em ácido nítrico 1:1 por, no mínimo, $24 \mathrm{~h}$. Os reatores de poli(tetrafluoretileno) (PTFE), empregados na digestão ácida, foram aquecidos com ácido nítrico 1:1 no mínimo por $4 \mathrm{~h}$. Gral de ágata e o pistilo, usados para homogeneizar as amostras reais, foram mergulhados em ácido nítrico $10 \%$ v/v por, no mínimo, 48 h e lavados com água em abundância.

\section{Soluções e reagentes}

Para o preparo de todas as soluções de calibração e para a mineralização das amostras foram utilizados reagentes com elevado grau de pureza. Mais especificamente, o procedimento incluiu as seguintes soluções: solução padrão multielementar Merck IV (Darmstadt, Alemanha, no 90392573) para preparar soluções intermediárias dos elementos $\mathrm{Ag}, \mathrm{Cd}, \mathrm{Cu}, \mathrm{Cr}, \mathrm{Mn}, \mathrm{Ni}, \mathrm{Pb}$ e $\mathrm{Zn}$; solução padrão de $\mathrm{Hg}$ da Merck (no 80309631); soluções padrão monoelementares de As, Se, Sn e V da SPEX (Edison, NJ, USA, no 08831R, 10831DM, 01911K e 01921Q, respectivamente). Todas elas foram preparadas com água com resistividade de $18 \mathrm{M} \Omega . c m$, obtida no sistema Milli-Q (Millipore, Bedford, M.A., USA). O ácido nítrico da Carlo Erba (Milão, Itália, no 408015) e o ácido clorídrico da Merck (nº 334), empregados no preparo das soluções, foram destilados abaixo dos seus pontos de ebulição em um destilador de quartzo da Hans Kürner Analysentechnik (Rosenheim, Alemanha).

\section{Digestão das amostras}

Para a análise dos animais, treze indivíduos de cada espécie foram coletados em cada ponto e transportados imediatamente ao laboratório, em caixa de isopor com gelo. Em seguida, (1) para a limpeza da parte externa da concha foram retiradas as incrustações de limo; (2) procedeu-se à pesagem do animal; (3) abriu-se o animal com uma espátula de aço inoxidável recoberta com teflon, liberando-se a água intervalar; (4) retirou-se o animal da concha, para a medição do peso da carne e, finalmente, (5) foram armazenadas as amostras em potes de vidro etiquetados, $\mathrm{a}-85^{\circ} \mathrm{C}$.

Posteriormente, procedeu-se à homogeneização da carne em gral de ágata para se obter uma massa homogênea, retirando-se a água intervalar mediante uma peneira de polietileno. Determinou-se a umidade, colocando-se alíquotas de um a dois gramas da amostra, em vidro de relógio previamente pesado, em dessecador contendo ácido sulfúrico.

Para a determinação de metais dissolvidos em águas marinhas superficiais foram coletadas 3 amostras de cada ponto em frascos de polietileno. As amostras, tão logo chegaram no laboratório, foram filtradas em membrana Millipore de 0,45 $\mu \mathrm{m}$ e só então acidificadas, seguindo o procedimento do método 3010B da Environmental Protection Agency, USA (EPA) e o protocolo dos métodos padronizados para a análise de metais ${ }^{19}$. Posteriormente, foram analisadas 
MAPA DAS ÁREAS ANALISADAS NA PESQUISA

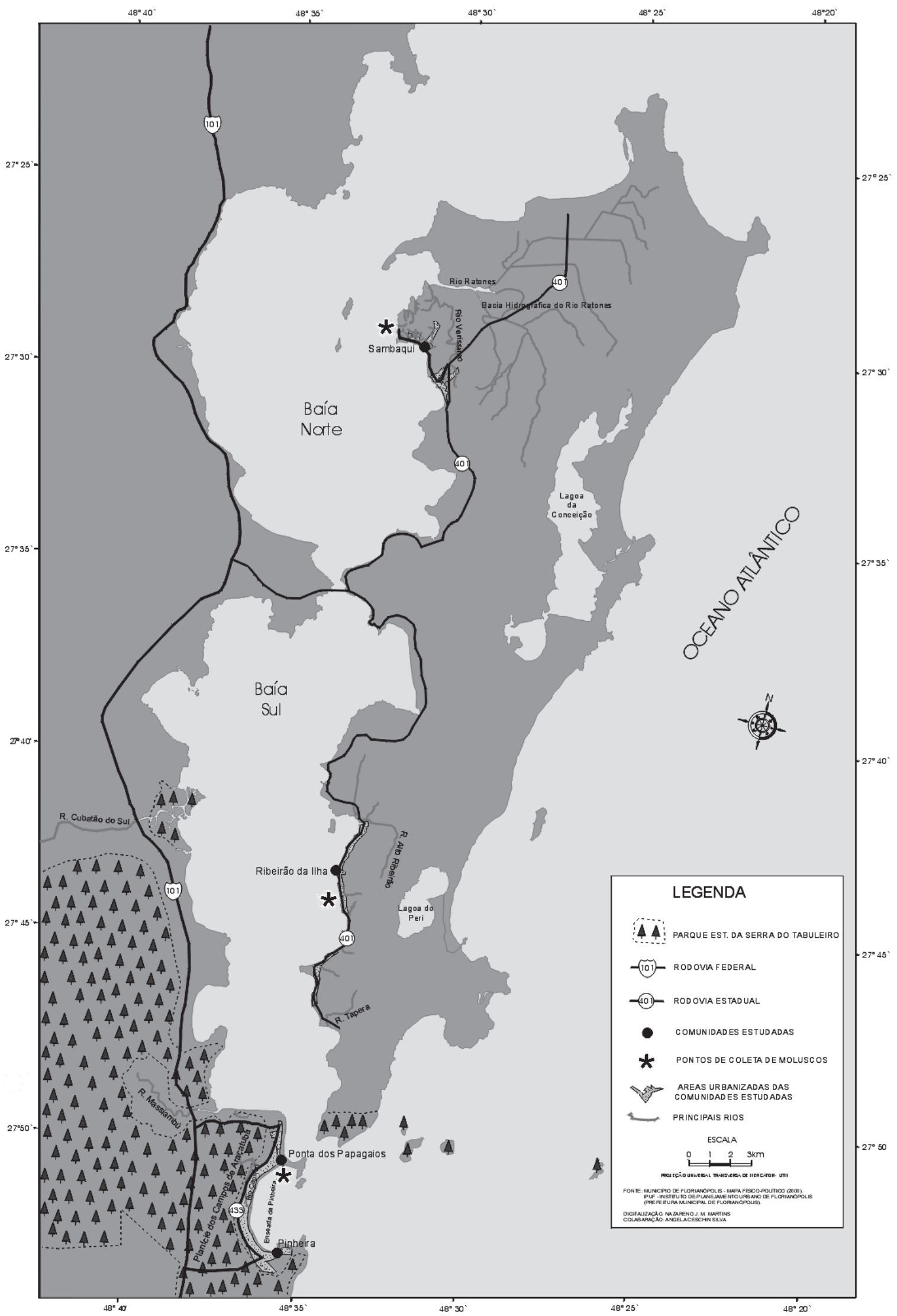

Figura 1. Localização dos pontos de amostragem, áreas de cultivo nas proximidades da Ilha de Santa Catarina (* Pontos de coleta de moluscos: Pinheira; Ribeirão da Ilha e Sambaquí) 
por espectrometria de massa com fonte de plasma indutivamente acoplado com introdução da amostra por vaporização eletrotérmica (ETV-ICP-MS) ${ }^{32}$, determinando-se diretamente As, Ag, Cr, Mn, Ni e V. A calibração foi realizada com ajuste de matriz com padrões preparados em água do mar purificada, na qual elementos traço foram previamente removidos por troca iônica em coluna de sílica imobilizada com 8-hidroxiquinoleína. Para As, utilizou-se o método da adição do analito ${ }^{25}$. Após separação da matriz por complexação/ sorção $0^{32}$ foram determinados $\mathrm{Cd}, \mathrm{Cu}, \mathrm{Pb}$ e Se, através de um sistema de injeção em fluxo acoplado e usando-se calibração externa, submetendo-se as soluções de calibração ao mesmo procedimento de separação. A exatidão dos métodos foi comprovada pela análise de água do mar certificada NASS-5 "Seawater Reference Material for Trace Metals" do National Research Council Canada. Na fração retida no filtro, determinaram-se os metais e semi-metais em suspensão, após digestão do filtro com ácido nítrico diluído (1:1) sob aquecimento em bloco digestor e a amostra levada ao volume original com água de alta pureza. As amostras foram analisadas quantitativamente por calibração externa, com a introdução da amostra por nebulização pneumática. Para se verificar o balanço das massas, 3 amostras integrais de água do mar, acidificadas in situ, foram tratadas de acordo com o método 3030E da EPA, e a determinação dos metais e semimetais realizada por ICP-MS, da mesma maneira descrita para os metais dissolvidos.

\section{RESULTADOS E DISCUSSÃO}

\section{Métodos e técnicas}

Em março de 2000 o Laboratório de Espectrometria Atômica da UFSC iniciou seus trabalhos de registro da qualidade dos resultados no âmbito do Projeto AQUACON MedBas, desenvolvido no Instituto de Meio Ambiente da Comunidade Européia, Ispra (Itália). Participou neste sentido dos exercícios de inter-calibração de resultados analíticos para uma série de amostras. Esta participação pode ser considerada de alta relevância para um laboratório que trabalha com amostras complexas e em níveis muito baixos (nível traço), já que permite identificar e eliminar erros sistemáticos, os quais são difíceis de serem percebidos dentro do mesmo ambiente laboratorial ${ }^{3,19,33-35}$. Os resultados obtidos pelo laboratório tiveram ótima concordância com os valores médios relatados.

Mesmo assim, a metodologia analítica empregada na análise de moluscos e das águas nos locais de cultivo foi previamente aplicada a amostras certificadas para validação da metodologia. Os valores de concentração obtidos para água de mar certificada NASS-5 tiveram uma boa concordância com os valores certificados. Para V o valor não é certificado (Tabela 1).

Por sua vez, os valores obtidos para o "Oyster Tissue" (Tabela 2) concordaram também com os valores certificados. Para o Sn o valor não é certificado. Segundo a própria agência de certificação, este elemento não se distribui homogeneamente no tecido mole de moluscos bivalves.

\section{Parâmetros físico-químicos na água do mar}

Os parâmetros na Tabela 3 podem ser considerados como normais, quando comparados com a bibliografia disponível internacionalmente ${ }^{36-38}$. De fato, o pH da água do mar situou-se em torno de 8,0 em todos os pontos de cultivo, sendo que a temperatura da mesma variou de 18 a $27^{\circ} \mathrm{C}$ entre os meses de abril e outubro. Os valores de salinidade e oxigênio dissolvido podem ser considerados adequados e consistentes com uma região em equilíbrio ${ }^{36-40}$, e estão de acordo com as temperaturas encontradas. A ampla faixa de variação des-
Tabela 1. Resultados da análise de material certificado de água do $\operatorname{mar}^{\mathrm{a}}$

\begin{tabular}{cccc}
\hline Isótopo & $\begin{array}{c}\text { Valor certificado } \\
\left(\mu \mathrm{g} . \mathrm{L}^{-1}\right)\end{array}$ & $\begin{array}{c}\text { Valor encontrado } \\
\left(\mu \mathrm{g} . \mathrm{L}^{-1}\right)\end{array}$ & $\begin{array}{c}\mathrm{L} . \mathrm{D} \\
\left(\mu \mathrm{g} . \mathrm{L}^{-1}\right)\end{array}$ \\
\hline${ }^{51} \mathrm{~V}$ & $1,2^{\mathrm{b}}$ & $0,9 \pm 0,1$ & 0,06 \\
${ }^{53} \mathrm{Cr}$ & $0,110 \pm 0,015$ & $0,132 \pm 0,021$ & 0,1 \\
${ }^{55} \mathrm{Mn}$ & $0,919 \pm 0,057$ & $0,986 \pm 0,120$ & 0,03 \\
${ }^{60} \mathrm{Ni}$ & $0,253 \pm 0,028$ & $0,262 \pm 0,046$ & 0,03 \\
${ }^{65} \mathrm{Cu}$ & $0,297 \pm 0,046$ & $0,240 \pm 0,074$ & 0,03 \\
${ }^{75} \mathrm{As}$ & $1,27 \pm 0,12$ & $1,29 \pm 0,04$ & 0,05 \\
${ }^{202} \mathrm{Hg}$ & - & $0,302 \pm 0,024$ & 0,01 \\
${ }^{208} \mathrm{~Pb}$ & $0,008 \pm 0,005$ & $\mathrm{Nd}^{\mathrm{c}}$ & 0,003 \\
\hline
\end{tabular}

$\bar{a}$ Amostra de material certificado de água do mar, NASS-5 (n=3) e limites de detecção (L.D., $3 s / a$, onde $s=$ desvio padrão medido; $a=$ inclinação da curva analítica, $\mathrm{n}=10$ ); ${ }^{\mathrm{b}}$ Valor informado; ${ }^{\mathrm{c}} \mathrm{Nd}=$ não determinado.

Tabela 2. Resultados obtidos na análise de material certificado de ostra $^{\mathrm{a}}$

\begin{tabular}{cccc}
\hline Isótopo & $\begin{array}{c}\text { Valor certificado } \\
\left(\mathrm{mg} \cdot \mathrm{kg}^{-1}\right)\end{array}$ & $\begin{array}{c}\text { Valor encontrado } \\
\left.\left(\mathrm{mg}^{\mathrm{kg}}\right)^{-1}\right)\end{array}$ & $\begin{array}{c}\mathrm{L} . \mathrm{D} \\
\left(\mathrm{mg} \cdot \mathrm{kg}^{-1}\right)\end{array}$ \\
\hline${ }^{51} \mathrm{~V}$ & $4,68 \pm 0,15$ & $3,95 \pm 0,08$ & 0,02 \\
${ }^{53} \mathrm{Cr}$ & $1,43 \pm 0,46$ & $1,52 \pm 0,25$ & 0,07 \\
${ }^{55} \mathrm{Mn}$ & $12,3 \pm 1,5$ & $10,2 \pm 0,1$ & 0,6 \\
${ }^{60} \mathrm{Ni}$ & $2,25 \pm 0,44$ & $2,49 \pm 0,04$ & 0,06 \\
${ }^{63} \mathrm{Cu}$ & $66,3 \pm 4,3$ & $67,0 \pm 0,8$ & 0,01 \\
${ }^{66} \mathrm{Zn}$ & $850 \pm 49$ & $824 \pm 54$ & 0,2 \\
${ }^{75} \mathrm{As}$ & $14 \pm 1,2$ & $12,8 \pm 0,1$ & 0,02 \\
${ }^{82} \mathrm{Se}$ & $2,21 \pm 0,24$ & $2,26 \pm 0,53$ & 0,2 \\
${ }^{107} \mathrm{Ag}$ & $1,68 \pm 0,15$ & $1,82 \pm 0,16$ & 0,005 \\
${ }^{114} \mathrm{Cd}$ & $4,15 \pm 0,38$ & $4,44 \pm 0,10$ & 0,003 \\
${ }^{120} \mathrm{Sn} *$ & 3 & $1,6 \pm 0,3$ & 0,002 \\
${ }^{208} \mathrm{~Pb}$ & $0,371 \pm 0,014$ & $0,363 \pm 0,022$ & 0,02 \\
\hline
\end{tabular}

a Oyster Tissue SRM 1566a (n=3), limites de detecção (L.D., 3s/a, $\mathrm{n}=10$ )

tes parâmetros está relacionada ao fato de se tratar de áreas localizadas nas proximidades da costa e com baixa profundidade (até $2 \mathrm{~m}$ ).

Com relação ao material particulado total (MPT), salienta-se o fato de que a maior parte se constitui de material inorgânico. Este dado é muito importante tendo-se em vista uma avaliação das possibilidades que os locais selecionados oferecem para a continuidade das atividades de aqüicultura, no futuro. De fato, as regiões costeiras pouco profundas e marcadas pela ausência de correntes significativas que respondem pela movimentação intensa e constante das águas podem enfrentar dificuldades neste sentido. É sabido, por exemplo, que em ambientes com pouca movimentação das águas, mais de $50 \%$ da produção primária chega a sedimentar-se através da coluna d'água. Em consequiência, a maior parte da matéria particulada orgânica é mineralizada no sedimento, e os produtos de sua decomposição acabam retornando à coluna d'água. Assim o conhecimento da associação dos metais com a matéria particulada ou sua presença na forma dissolvida torna-se relevante na caracterização da provável origem deste tipo de contaminação e na busca de estratégias para sua minimização ${ }^{38}$.

\section{Faixas de concentração de metais e semi-metais na água do mar}

A Tabela 4 apresenta as faixas de concentração obtidas no decorrer dos quatro períodos de coletas realizadas, para elementos traço 
Tabela 3. Parâmetros físico-químicos de água do mar nos locais de cultivo e a variação ao longo do ano

\begin{tabular}{|c|c|c|c|c|c|c|}
\hline & Abril 1999a & Outubro $1999^{a}$ & MM 1999b & Abril 2000 & Outubro $2000^{\mathrm{a}}$ & MM $2000^{b}$ \\
\hline \multicolumn{7}{|c|}{ SAMBAQUÍ } \\
\hline $\mathrm{pH}$ & $7,7(0,2)$ & $8,2(0,1)$ & $7,7-8,5$ & $8,1(0,2)$ & $8,1(0,1)$ & $8,0-8,5$ \\
\hline Temp. $\left({ }^{\circ} \mathrm{C}\right)$ & $22,1(0,2)$ & $22,2(0,3)$ & $17,8-28,1$ & $23,2(0,1)$ & $21,8(0,1)$ & $14,3-27,2$ \\
\hline $\mathrm{O}_{2}(\mathrm{mg} / \mathrm{L})$ & $7,5(0,2)$ & $10,2(0,1)$ & $5,8-10,2$ & $7,5(0,1)$ & $5,4(0,2)$ & $5,1-10,2$ \\
\hline Salinidade $(\% o)$ & $33,1(0,1)$ & $34,0(0,2)$ & $30,2-35,0$ & $33,0(0,2)$ & $31,7(0,1)$ & $30,5-35,0$ \\
\hline Turbidez & $6,4(0,8)$ & $9,4(0,7)$ & $3,8-23,3$ & $10,2(0,3)$ & $7,1(2,7)$ & $4,0-90,6$ \\
\hline MPT (mg/L) & $10,7(0,7)$ & $16,3(2,1)$ & $4,6-60,4$ & $12,5(2,2)$ & $16,8(1,5)$ & $6,1-42,8$ \\
\hline MIP (mg/L) & $9,1(0,5)$ & $14,2(1,6)$ & $4,1-51,4$ & $10,6(1,8)$ & $15,1(1,4)$ & $5,1-75,0$ \\
\hline MOP (mg/L) & $1,5(0,2)$ & $2,1(0,5)$ & $0,5-9,0$ & $1,9(0,4)$ & $1,6(0,1)$ & $1,0-15,2$ \\
\hline Clorofila $a(\mu \mathrm{g} / \mathrm{L})$ & $4,8(0,2)$ & $3,2(0,1)$ & $1,8-8,3$ & $5,5(0,4)$ & $4,4(0,2)$ & $1,1-7,0$ \\
\hline \multicolumn{7}{|c|}{ RIBEIRÃO } \\
\hline $\mathrm{pH}$ & $7,8(0,2)$ & $8,2(0,1)$ & $7,5-8,5$ & $8,2(0,1)$ & $7,5(0,2)$ & $7,5-8,3$ \\
\hline Temp. $\left({ }^{\circ} \mathrm{C}\right)$ & $20,4(0,1)$ & $19,0(0,2)$ & $16,0-29,7$ & $22,3(0,3)$ & $23,5(0,2)$ & $13,5-24,8$ \\
\hline $\mathrm{O}_{2}(\mathrm{mg} / \mathrm{L})$ & $7,8(0,2)$ & - & $6,2-10,2$ & $7,8(0,1)$ & $8,3(0,6)$ & $2,7-8,9$ \\
\hline Salinidade $(\% o)$ & $33,8(0,1)$ & - & $29,9-35,0$ & $34,0(0,5)$ & $29,7(0,1)$ & $29,6-34,8$ \\
\hline Turbidez & $5,7(1,2)$ & $7,5(1,0)$ & $2,2-8,5$ & $3,3(0,3)$ & $3,8(0,5)$ & $1,0-7,9$ \\
\hline MPT (mg/L) & $7,2(0,6)$ & $12,2(1,0)$ & $2,5-13,9$ & $5,9(0,9)$ & $9,9(0,4)$ & $3,3-37,2$ \\
\hline MIP (mg/L) & $6,5(0,6)$ & $10,5(0,8)$ & $2,0-14,7$ & $4,3(0,8)$ & $7,2(0,4)$ & $2,1-29,6$ \\
\hline MOP (mg/L) & $0,7(0,2)$ & $1,7(0,2)$ & $0,1-2,7$ & $1,5(0,1)$ & $2,8(0,1)$ & $0,3-7,5$ \\
\hline Clorofila $a(\mu \mathrm{g} / \mathrm{L})$ & $1,3(0,1)$ & $3,1(0,2)$ & $1,3-6,0$ & $2,8(0,4)$ & $5,8(0,3)$ & $0,7-7,0$ \\
\hline \multicolumn{7}{|c|}{ PINHEIRA } \\
\hline $\mathrm{pH}$ & $8,3(0,2)$ & $8,2(0,1)$ & $7,5-8,5$ & $8,3(0,2)$ & $7,9(0,1)$ & $7,5-8,5$ \\
\hline Temp. $\left({ }^{\circ} \mathrm{C}\right)$ & $21,6(0,1)$ & $20,8(0,3)$ & $15,6-26,7$ & $21,5(0,1)$ & $20,2(0,2)$ & $14,9-22,7$ \\
\hline $\mathrm{O}_{2}(\mathrm{mg} / \mathrm{L})$ & $6,7(0,2)$ & $10,2(0,3)$ & $5,4-10,2$ & $7,0(0,2)$ & $8,3(0,5)$ & $6,0-8,7$ \\
\hline Salinidade (\%o) & $34,6(0,1)$ & $37,0(0,2)$ & $30,8-37,0$ & $35,2(0,1)$ & $34,7(0,2)$ & $29,7-36,1$ \\
\hline Turbidez & $3,5(0,2)$ & $3,1(1,2)$ & $0,8-20,6$ & $3,5(0,4)$ & $4,2(1,2)$ & $0,6-12,6$ \\
\hline MPT (mg/L) & $11,0(5,5)$ & $22,9(17,6)$ & $1,3-40,5$ & $8,6(1,7)$ & $6,2(1,6)$ & $2,6-56,0$ \\
\hline MIP (mg/L) & $8,9(4,5)$ & $18,2(13,4)$ & $0,8-31,6$ & $7,3(1,8)$ & $4,4(0,4)$ & $1,5-46,9$ \\
\hline MOP (mg/L) & $2,4(0,7)$ & $4,8(4,1)$ & $0,2-8,9$ & $1,3(0,1)$ & $1,9(0,3)$ & $0,4-9,2$ \\
\hline Clorofila $a(\mu \mathrm{g} / \mathrm{L})$ & $1,3(0,1)$ & $2,1(0,1)$ & $0,7-5,1$ & $1,6(0,2)$ & $2,4(0,2)$ & $0,5-7,6$ \\
\hline
\end{tabular}

a Valores médios e desvios padrão (entre parênteses); ${ }^{\mathrm{b}}$ os valores de MM representam a mínima e a máxima na variação ao longo do ano, o fundo foi sempre menor que $2 \mathrm{~m} ;{ }^{\mathrm{c}} \mathrm{MPT}=$ matéria particulada total, MOP = matéria orgânica e MIP = matéria inorgânica em suspensão.

Tabela 4. Faixas de concentrações de metais e semi-metais em água do mar nas quatro coletas realizadas e valores permitidos pelo CONAMA $^{7}$

\begin{tabular}{lcc}
\hline Elemento & $\begin{array}{c}\text { Faixa encontrada } \\
\mu \mathrm{g} . \mathrm{L}^{-1}\end{array}$ & $\begin{array}{c}\text { Máximo valor permitido } \\
\text { pelo CONAMA } \\
\mu \mathrm{g} . \mathrm{L}^{-1}\end{array}$ \\
\hline Arsênio & $1,1-2,4$ & 50,0 \\
Cádmio & $0,01-0,15$ & 5,0 \\
Chumbo & $0,1-0,7$ & 10,0 \\
Cobre & $0,4-8,5$ & 50,0 \\
Cromo & $0,7-3,7$ & 50,0 \\
Manganês & $0,4-9,0$ & 100,0 \\
Níquel & $0,2-5,2$ & 100,0 \\
Selênio & $0,05-1,3$ & 10,0 \\
\hline
\end{tabular}

na forma dissolvida em água do mar em todos as áreas de cultivo em estudo. Nesta mesma tabela foram incluídos, para fins de comparação, os valores autorizados pelo CONAMA 4 para o trabalho de gestão de águas Classe 5 (tipo de classificação para águas salinas destinadas à aqüicultura). Seria importante observar que, para os metais e o semi-metal As estudados, foram obtidos valores inferiores aos permitidos pela legislação em vigor. No entanto, vale a pena ressaltar que a legislação brasileira não faz referência à forma dos metais, ou seja, não especifica se os resultados devem ser apresentados na forma total, dissolvida ou na matéria em suspensão nas águas em estudo. Permanece também pouco claro se os valores permitidos na Legislação CONAMA No 20, para estes elementos químicos, podem ser considerados superiores àqueles permitidos nas legislações da maioria dos países da Comunidade Européia e, também, Japão e Estados Unidos, que já passaram por problemas graves de contaminação de metais no passado. A médio e longo prazo será necessário compatibilizar a metodologia de análise e legislação brasileira com a de outros países, em função das exigências de mercados econômicos globalizados. Cita-se, como exemplo, as normas reconhecidas pela "Association of Official Analytical Chemists (AOAC)", através das quais as ações de segurança de qualidade são estabelecidas e os sistemas de qualidade são padronizados e reconhecidos (normas BS 5750 / BS EN ISO 9000, NAMAS M10, ISO Guide 25, EN 45001) $)^{3,41}$.

A Tabela 5 permite visualizar os resultados da distribuição dos metais nas frações dissolvida e particulada em todos os pontos de coleta de dados. A importância dos dados físico-químicos pode ser ilustrada analisando-se o caso do $\mathrm{Cu}$. A concentração de $\mathrm{Cu}$ em águas de 
Tabela 5. Valores médios de concentração de elementos traço na fração dissolvida (D) e na fração particulado (P) da água do mar, nas diferentes regiões em estudo. ${ }^{a}$

\begin{tabular}{|c|c|c|c|c|c|c|}
\hline \multirow[b]{3}{*}{ Pinheira } & \multicolumn{2}{|c|}{ As } & \multicolumn{2}{|c|}{$\mathrm{Cd}$} & \multicolumn{2}{|c|}{$\mathrm{Cr}$} \\
\hline & $\mathrm{D}$ & $\mathrm{P}$ & $\mathrm{D}$ & $\mathrm{P}$ & $\mathrm{D}$ & $\mathrm{P}$ \\
\hline & $2,4 \pm 0,1$ & $0,7 \pm 0,1$ & $0,11 \pm 0,03$ & $0,22 \pm 0,01$ & $0,7 \pm 0,1$ & $5,1 \pm 0,6$ \\
\hline Ribeirão & $1,8 \pm 0,1$ & $1,11 \pm 0,03$ & $0,03 \pm 0,01$ & $0,08 \pm 0,01$ & $1,7 \pm 0,3$ & $2,6 \pm 0,4$ \\
\hline \multirow[t]{2}{*}{ Sambaqui } & $2,2 \pm 0,1$ & $0,66 \pm 0,03$ & $0,02 \pm 0,01$ & $0,05 \pm 0,01$ & $2,4 \pm 0,3$ & $2,4 \pm 0,4$ \\
\hline & \multicolumn{2}{|c|}{$\mathrm{Cu}$} & \multicolumn{2}{|c|}{$\mathrm{V}$} & \multicolumn{2}{|c|}{$\mathrm{Mn}$} \\
\hline Pinheira & $1,2 \pm 0,4$ & $1,1 \pm 0,1$ & $0,9 \pm 0,1$ & $1,1 \pm 0,1$ & $4,4 \pm 0,4$ & $19,8 \pm 0,1$ \\
\hline Ribeirão & $3,8 \pm 1,0$ & $2,2 \pm 0,2$ & $1,7 \pm 0,1$ & $2,2 \pm 0,2$ & $9,1 \pm 0,6$ & $15,7 \pm 0,6$ \\
\hline \multirow[t]{2}{*}{ Sambaqui } & $1,3 \pm 0,2$ & $5,1 \pm 0,3$ & $3,7 \pm 0,5$ & $5,1 \pm 0,3$ & $3,5 \pm 0,2$ & $14,7 \pm 0,7$ \\
\hline & \multicolumn{2}{|c|}{$\mathrm{Ni}$} & \multicolumn{2}{|c|}{$\mathrm{Pb}$} & \multicolumn{2}{|c|}{$\mathrm{Se}$} \\
\hline Pinheira & $0,27 \pm 0,06$ & $0,3 \pm 0,1$ & $0,32 \pm 0,07$ & $0,8 \pm 0,2$ & $1,0 \pm 0,2$ & $2,3 \pm 0,7$ \\
\hline Ribeirão & $0,24 \pm 0,05$ & $0,3 \pm 0,1$ & $0,4 \pm 0,1$ & $1,3 \pm 0,4$ & $0,9 \pm 0,2$ & $2,0 \pm 0,1$ \\
\hline Sambaqui & $2,8 \pm 0,4$ & $3,3 \pm 0,6$ & $0,21 \pm 0,04$ & $0,27 \pm 0,08$ & $1,2 \pm 0,2$ & $1,8 \pm 0,3$ \\
\hline
\end{tabular}

${ }^{a}$ Amostra de água do mar de outubro de $2000(n=6)$; resultados em $\mu$ g. $\mathrm{L}^{-1}$

regiões de estuários encontra-se, geralmente, entre 0,2 a $100 \mu \mathrm{g} . \mathrm{L}^{-1}$, sendo que em Santa Catarina, os valores observados nos diferentes pontos de coleta e diferentes períodos do ano (Figura 2) são muito menores que o teor máximo permitido pelo CONAMA, para águas catalogadas na classe 5 (50 $\mu \mathrm{g} . \mathrm{L}^{-1}$, Tabela 3). Conhecendo-se as constantes de estabilidade para os diferentes equilíbrios possíveis em água do mar, pode-se calcular a distribuição de espécies químicas, a qual é fortemente controlada pelo $\mathrm{pH}$. Em geral, as espécies mais abundantes do cobre são $\mathrm{Cu}(\mathrm{OH}) \mathrm{Cl}$ e $\mathrm{Cu}(\mathrm{OH})_{2}$, (aproximadamente $65 \%$ do $\mathrm{Cu}$ total), sendo que o nível de $\mathrm{Cu}(\mathrm{OH})_{2}$ aumenta de $18 \%$ do cobre total em pH 7,0 a $90 \%$ em pH 8,6; enquanto que o $\mathrm{CuCO}_{3}$ decresce de $30 \%$ em pH 7,0 para menos de $0,1 \%$ em pH 8,6. Estes dados são relevantes na medida em que afetam a biodisponibilidade e toxicidade do cobre em ecossistemas marinhos, a qual é promovida por quelantes orgânicos sintéticos solúveis ${ }^{42}$. A análise da Tabela 5 permite-nos constatar a maior associação de $\mathrm{Cu}, \mathrm{Mn}, \mathrm{Ni}$ e $\mathrm{Pb}$ com a fração particulada, em sintonia com os resultados apresentados na bibliografia disponível ${ }^{17,20,43}$. Trata-se de um resultado esperado, mas que indica a necessidade de se verificar, em futuros trabalhos de avaliação, a presença dos metais e metalóides na fase sedimentária dos locais de cultivo selecionados, principalmente por causa da baixa profundidade e da falta de correntes importantes nas áreas de cultivo.

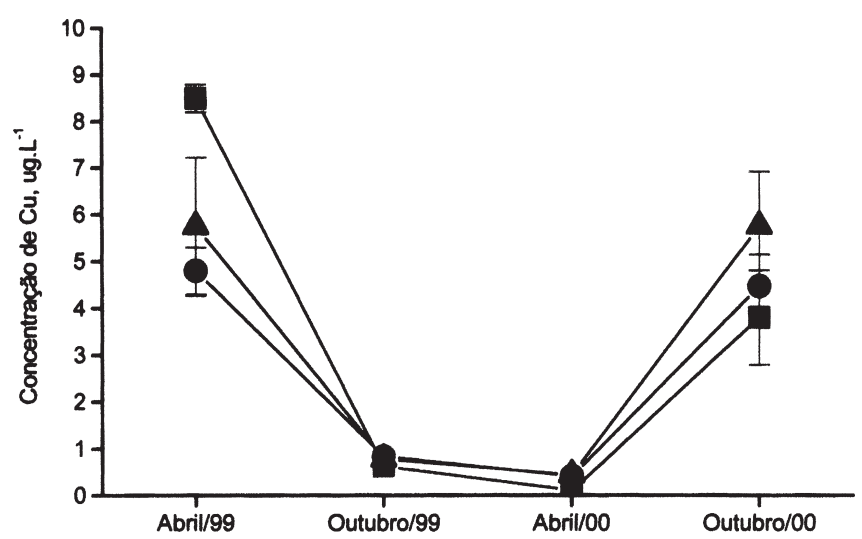

Figura 2. Representação dos teores médios e desvios padrão (barras verticais) de Cu em água do mar nos diferentes pontos de amostragem ( $\mathbf{\Delta}$ Pinheira -Ribeirão -Sambaquí) em diferentes coletas (n=6)

\section{Resultados das análises em moluscos}

Quando comparados os níveis de $\mathrm{Cu}$ em mexilhões e ostras, Tabela 6 e Figura 3, percebe-se que as ostras acumulam este elemento num fator de até 10 vezes mais que os mexilhões em todos os pontos de cultivo e datas de amostragem estudadas. $\mathrm{O}$ mesmo resultado foi observado por O'Connor ${ }^{12}$ em trabalho com ostras Crassostrea virginica e Ostrea sandvicensis e com mexilhões Mytilus edulis e Mytilus californianus. Um comportamento semelhante é observado para Cd e, também, Zn, que se acumulam mais em ostras, porém em proporções menores, de 1,7 a 3,5 vezes (ver Tabela 6). Para Ni a acumulação é maior no mexilhão, sendo que esta diferença chegou até um fator de 10 vezes em Sambaquí, na coleta de outubro de 1999 e, na média, foi um fator de 5,7 vezes superior.

A Tabela 6 apresenta os valores encontrados (faixas de concentração) em moluscos para metais e semi-metais e, inclui - para fins comparativos - valores encontrados em outros programas de monitoramento ambiental. Os dados representam os metais e semimetais em suas formas totais sendo que, em ambientes marinhos, os principais fatores que influem nos processos que determinam o efeito dos metais e semi-metais são a hidrólise, a precipitação, a adsorção e a bioacumulação dos mesmos ${ }^{38,40}$. Assim, a toxicidade dos elementos metálicos e semi-metais para a biota aquática é significativamente influenciada por variáveis abióticas como dureza, temperatura, pH e salinidade da água, que afetam a distribuição de espécies, e fatores biológicos como espécie, estágio de vida, e diferenças potenciais em sensibilidade da população local ${ }^{40,42}$. Finalmente, é importante salientar que, em todos os casos, os teores encontrados estão abaixo dos limites toleráveis citados em "Food and Drugs Administration (FDA) Guidance Document" e são semelhantes aos níveis descritos em outros programas de monitoramento criados no cenário internacional (ver Tabela 6).

Com relação às formas químicas presentes em ambientes marinhos, as espécies $\mathrm{Cr}(\mathrm{III})$ e $\mathrm{Cr}(\mathrm{VI})$ merecem atenção especial, já que podem existir em sítios onde os teores de matéria orgânica presentes na água são baixos ${ }^{45}$. O Cr(VI) encontrado na natureza é altamente tóxico e aparece com resultado de emissões domésticas e industriais. Geralmente é a espécie dissolvida mais estável e predominante na água do mar sob condições normais de oxigênio. De fato, $\mathrm{Cr}$ (III) pode ser facilmente oxidado a $\mathrm{Cr}(\mathrm{VI})$ por óxidos de manganês, normalmente presentes nos sedimentos ${ }^{17}$.

Por último, o semi-metal As também merece destaque, em fun- 
Tabela 6. Faixa de valores determinados para alguns metais e semi-metais em moluscos (valores em mg.kg-1 de peso seco)

\begin{tabular}{|c|c|c|c|c|c|}
\hline & Costa USA ${ }^{1,22}$ & Costa do Chile ${ }^{24}$ & Groelândia ${ }^{25}$ & Ilha de Santa Catarina & Limite de tolerância \\
\hline As & $8,28-10,20$ & - & $9,79-16,1$ & $\begin{array}{c}8,0-18,0 \\
(13,4)^{\mathrm{a}}(14,2)^{\mathrm{b}}\end{array}$ & $86^{*}$ \\
\hline $\mathrm{Cd}$ & $1,97-3,2$ & $2,1-20,0$ & $1,20-2,34$ & $\begin{array}{c}0,5-2,8 \\
(1,5)^{\mathrm{a}}(0,9)^{\mathrm{b}}\end{array}$ & $4^{*}$ \\
\hline $\mathrm{Cr}$ & - & - & $0,93-1,96$ & $\begin{array}{c}0,6-5,0 \\
(1,5)^{\mathrm{a}}(2,4)^{\mathrm{b}}\end{array}$ & $13^{*}$ \\
\hline $\mathrm{Cu}$ & $94-138^{a}$ & $90-134$ & $7,4-10,5$ & $\begin{array}{c}1,7-32,5 \\
(20,0)^{\mathrm{a}}(6,5)^{\mathrm{b}}\end{array}$ & $150 * *$ \\
\hline $\mathrm{Hg}$ & $0,09-0,12$ & $0,04-0,13$ & $0,05-0,10$ & $\begin{array}{c}0,01-0,33 \\
(0,096)^{\mathrm{a}}(0,16)^{\mathrm{b}}\end{array}$ & $1 *$ \\
\hline $\mathrm{Mn}$ & - & - & - & $\begin{array}{c}17,5-53,7 \\
(43,3)^{\mathrm{a}}(32,1)^{\mathrm{b}}\end{array}$ & \\
\hline $\mathrm{Ni}$ & $1,64-2,13$ & - & - & $\begin{array}{c}0,5-11,4 \\
(1,0)^{\mathrm{a}}(5,7)^{\mathrm{b}}\end{array}$ & $70 *$ \\
\hline $\mathrm{Pb}$ & $0,42-2,20$ & - & $0,89-2,50$ & $\begin{array}{c}0,1-1,7 \\
(0,9)^{\mathrm{a}}(0,6)^{\mathrm{b}}\end{array}$ & $1,7 *$ \\
\hline $\mathrm{Se}$ & $2,27-3,25$ & - & $3,22-5,56$ & $\begin{array}{c}1,6-4,6 \\
(2,5)^{\mathrm{a}}(3,1)^{\mathrm{b}}\end{array}$ & $30 * *$ \\
\hline $\mathrm{Sn}$ & - & - & - & $\begin{array}{c}0,01-0,07 \\
(0,03)^{\mathrm{a}}(0,03)^{\mathrm{b}}\end{array}$ & $250 * *$ \\
\hline $\mathrm{Zn}$ & $1633-2350^{c}$ & $200-233$ & $66,5-117$ & $\begin{array}{c}40-580 \\
(353)^{\mathrm{a}}(100)^{\mathrm{b}}\end{array}$ & $250 * *$ \\
\hline
\end{tabular}

${ }^{a}$ Média geral para teores obtidos em tecido de ostra; ${ }^{b}$ média geral para teores obtidos em tecido de mexilhão; ${ }^{\mathrm{c}}$ faixa obtida apenas em tecido de ostra. Os limites de tolerância para moluscos bivalves inicados de acordo com "Food and Drugs Administration (FDA) Guidance Document $^{44}$ " (*) e $\operatorname{ABIA}^{46}(* *)$.

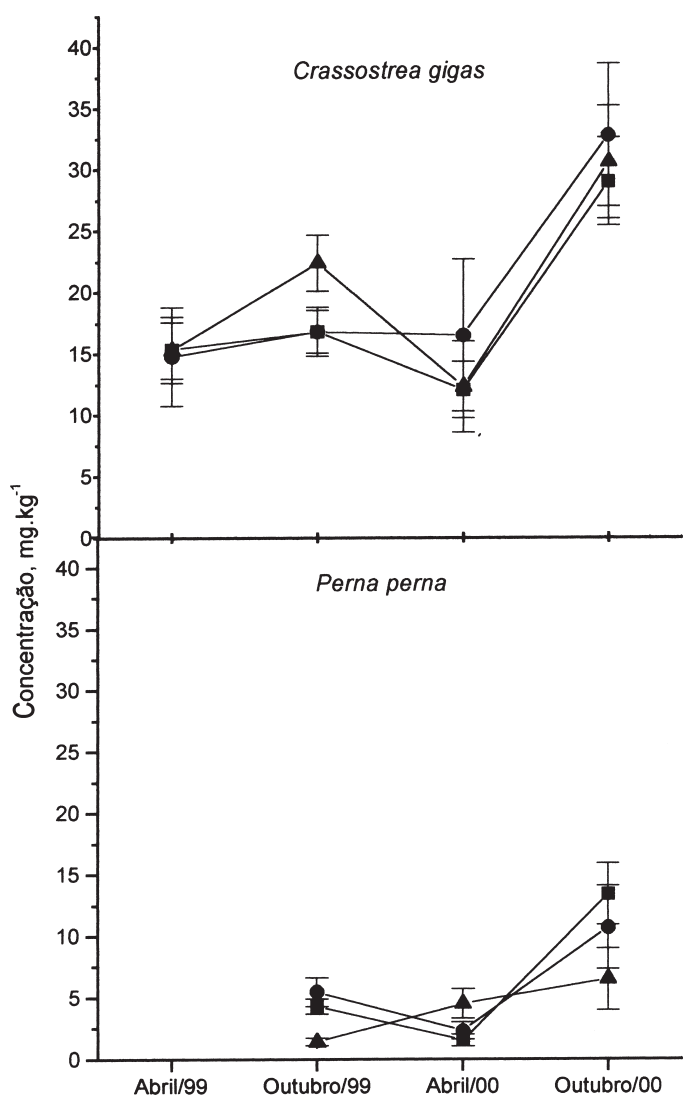

Figura 3. Média e desvio padrão dos teores de Cu para mexilhões e ostras nos diferentes pontos de cultivo ( $\mathbf{\Delta}$-Pinheira $\boldsymbol{\square}$-Ribeirão $\boldsymbol{Q}$-Sambaquí) $e$ coletas realizadas ( $n=13$ indivíduos $x 3$ replicatas por indivíduo). O teor médio de umidade foi de $80 \%$ ção do seu grau de periculosidade quando presente na forma inorgânica. Como pode ser observado na Tabela 6, as concentrações de As detectadas neste estudo são similares àquelas encontradas em outras áreas de cultivo mantidas em outros países. Além disso, quando comparamos os resultados encontrados com os limites de tolerância encontrados na bibliografia disponível, podemos concluir que os primeiros permanecem nitidamente inferiores. Cabe salientar que a tolerância de ingestão diária de arsênio está baseada na exposição ao arsênio na forma inorgânica. Porém, sabe-se que na maior parte dos casos o arsênio existente em frutos do mar encontra-se na forma orgânica. Apenas 10\% do As total encontrado em organismos marinhos apresenta-se na forma inorgânica ${ }^{44}$.

\section{CONCLUSÕES}

Os resultados das análises relativas à presença de metais e semimetais, e os procedimentos normais de controle da qualidade analítica foram submetidos a um exercício inter-laboratorial. Cabe destacar que este exercício é reconhecido pelos órgãos competentes como uma dimensão constitutiva do processo de certificação da qualidade dos produtos obtidos através da maricultura. $\mathrm{O}$ trabalho realizado gerou assim resultados que poderão servir de base para estudos futuros, orientados no sentido da definição de uma legislação específica para futuras atividades de maricultura sensíveis à problemática dos riscos socioambientais no Brasil.

A técnica de espectrometria de massa com fonte de plasma indutivamente acoplado mostrou-se eficiente na determinação total de metais presentes nas amostras selecionadas. Nas águas do mar submetidas à análise, todos os teores de metais encontram-se abaixo do limiar máximo permitido pela legislação brasileira (CONAMA) para águas de classe 5 (indicadas para atividades de aqüicultura).

Em síntese, os riscos de contaminação de moluscos por metais e semi-metais podem ser considerados, até o momento, pouco rele- 
vantes. Todavia, esta conclusão deve ser considerada com reservas, pelo fato de não ter sido ainda realizada uma avaliação suplementar sobre o estado atual dos sedimentos existentes nas áreas de cultivo selecionadas. Além disso, não deveriam ser minimizados os riscos atuais de contaminação dos cultivos por agentes bioquímicos e tóxicos, configurando um cenário preocupante em termos de gestão da qualidade ambiental que poderá ser corroborado ou atenuado no decorrer da próxima etapa do projeto.

\section{AGRADECIMENTOS}

Os autores agradecem ao apoio financeiro concedido pelo programa PADCT-III (CIAMB/ FINEP). Também agradecem aos autores do mapa apresentado: N. J. M. Martins e A. C. C. Silva.

\section{REFERÊNCIAS}

1. Roczanski, M.; Costa, S. W.; Boll, M. G.; Oliveira Neto, F. M.; Anais do XI Simpósio Brasileiro de Aqüicultura, Florianópolis, Brasil, 2000.

2. Bainy, A. C. D.; Seibert, E. L.; Ferreira, J. F.; Marques, M. R. F.; Vieira, P. F.; Arana, L.V.; Ceschin, A.; Roney, A.; Martins, N. J.; Sáenz, L. A.; Rosa, R.; Taffarel, I.; Fiedler, H. D.; Curtius, A. J.; Anais do XI Simpósio Brasileiro de Aqüicultura, Florianópolis, Brasil, 2000.

3. Günzler, H., ed.; Accreditation and Quality Assurance in Analytical Chemistry; Springer-Verlag: Germany, 1994.

4. Brasil. Decreto - lei $n^{\circ} 9.433$, de 8 de janeiro de 1997. Institui a Política Nacional de Recursos Hídricos onde a Resolução CONAMA № 20, de 18 de junho de 1986 está inserida. Diário Oficial [da República Federativa do Brasil], 30 julho 1986.

5. Norwegian Institute for Water Research, NIVA-Report, Preliminary proposals for classification of marine environmental quality respecting micropollutants in water, sediments and selected organisms, E-862602/O89266. Knutzen, J.; Skei, J.; Noruega, 1992.

6. Molvaer, J.; Knutzen, J; Magnusson, J.; Rygg, B.; Skei, J.; Sorensen, J.; Classification of environmental quality of fjords and coastal waters, State Pollution Control Authority (in Norwegian), Guide no. 97:03. 1997.

7. Gundersen, P.; Olsvik, P.A. e Steinnes, E.; Environ. Toxicol. Chem. 2001, 20, 978.

8. Peterson, C.; Jackson, J.; Kirby, M.; Lenihan, H.; Bourque, B.; Bradbury, R.; Cooke, R.; Kidwell, S.; Science. 2001, 293, 1590.

9. O' Connor, T. P.; Recent Trends in Coastal Environmental Quality: Results from the First Five Years of the NOAA Mussel Watch Project. Coastal Monitoring Branh Coast Monitoring and Bioeffects Assessment Division, $1-46,1990$.

10. Sampling and Analytical Methods of the National Status and Trends Program - National Benthic Surveillance and mussel Watch projects 19841992, vol. III, Lauenstein, G. G.; Cantillo, ed.; NOAA Technical Memorandum NOS ORCA 71, 1993.

11. O'Connor, T. P.; Mar. Environ. Res. 1996, 41, 183.

12. O’Connor, T. P.; Mar. Pollut. Bull. 1998, 37,14.

13. Bourgoin, B. P.; Risk, M. J.; Evans, R. D.; Cornett, R. J.; Water, Air and Soil Pollut. 1991, 57, 377.

14. DE Gregori, I.; Delgado, D.; Pinochet, H.; Sci. Total Environ. 1994, 148, 1.

15. Reeve, R.; Environmental Analysis: Analytical Chemistry by Open Learning, University of Greenwich: Chichester, 1994.
16. Allen, H. E.; Hansen, D. J.; Water Environ. Res. 1996, 68, 42.

17. Nome, R. A.; Mendiguchía-Martínez, C.; Nome, F.; Fiedler, H. D.; Environ. Toxicol. Chem. 2001, 20, 693.

18. Stumm, W.; Aquatic Surface Chemistry, John Wiley \& Sons, Inc.: USA, 1987.

19. Clesceri, L. S.; Greenberg, A. E.; Eaton, A. D.; Frason, M. A., eds.; Standard Methods for the Examination of Water and Wastewater, 20th. ed.; American Public Health Association, American Water Works Association, Water Environment Federation; United Book Press, Inc.: USA, 1998.

20. Salomons, W.; Förstner, U.; Metals in the Hydrocycle, Springer-Verlag: Germany, 1984.

21. Prigogine, I.; From Being to Becoming, Freeman: San Francisco, 1980.

22. Taylor, H. E.; Garbarino, J. R.; Analytical Aplications of Inductively Coupled Plasma-Mass Spectrometry; U. S. Geological Survey 3215 Marine Street Boulder, Colorado, 1992.

23. Seibert, E. L.; Fiedler, H. D.; Curtius, A. J.; SETAC 21 St. Annual Meeting, Nashville: USA, 2000.

24. Pozebon, D.; Dressler, V. L.; Curtius, A. J.; At. Spectrosc. 1998, 19, 80.

25. Gregoire, D. C.; Ballinas, M. D.; Spectrochim. Acta. Part B 1997, 52, 75.

26. Carley, M.; Bustelo, E.S.; Social Impact Assessment and Monitoring, Westview: Boulding, 1984.

27. Bromley, D. W., ed.; Making the Commons Work. Theory, Pactice and Policy. 1CS Press: San Francisco, 1992.

28. Vieira, P. F.; Weber, J.; Gestão de Recursos Naturais Renováveis e Desenvolvimento, Cortez: São Paulo, 1997.

29. Berkes, F.; Folke, C., eds.; Linking Social and Ecological Systems. Management Practices and Social Mechanisms for Building Resilience, Cambridge University Press: Cambridge, 1998.

30. Strickland, J. D. H.; Parsons, T. R.; A Pratical Handbook of Seawater Analysis, 2. (F.R.B.Can. Bulletin, 167). Ottawa: Queen's Printer, 1972.

31. Littlepage, J. L.; Oceanografia: Manual de Técnicas Oceanográficas para Trabalhos em Laboratório e a Bordo, Fortaleza: EUFC, 1998.

32. Dressler, V. L.; Pozebon, D.; Curtius, A. J.; Spectrochim. Acta $53 B$ 1998, 1527

33. Kateman, G.; Buydens, L.; Quality Control in Analytical Chemistry, Winefordner, J. D.; Kolthoff, I. M., Ed.; A Wiley-Interscience publications: New York, 1993.

34. EN 45002. General criteria for asssessment of testing laboratories. The Joint European Standards Institution, Rue Brederode 2, B-1000 Brussels, Belgium, 1989.

35. Alexandrov, Y. I.; Analyst 1996, 121, 1137.

36. http://www.utdallas.edu/ mitterer, acessada em Janeiro 2001.

37. http://www.chemetrics.com, acessada em Dezembro 2001.

38. Stumm, W.; Morgan, J. J.; Aquatic Chemistry. Chemical Equilibria and Rates in Natural Waters, $3^{\text {a }}$ ed., John Wiley \& Sons, Inc.: USA, 1996.

39. Huettel, M.; Ziebis, W.; Forster, S.; Limnol. Oceanogr. 1996, 41, 309.

40. Manahan, S. E.; Environmental Chemistry, $6^{\mathrm{a}}$ ed., CRC Press, Inc.: USA, 1994.

41. Em Analytical Chemistry by O. L. Autora coordenadora, Prichard, F. E., Ed. ACOL, John Wiley \& Sons., Inc.: UK, 1998.

42. Eisler, R.; Handbook of Chemical Risk Assessment, Health Hazards to Humans, Plants and Animals, vol. 1, Lewis Publishers: New York, 2000.

43. Lima, M. C.; Giacomelli, M. B. O.; Stüpp, V.; Roberge, F. D.; BermejoBarrera, P.; Quim. Nova 2001, 24, 734.

44. http://www.cfsan.fda.gov, acessada em Fevereiro 2002.

45. Walsh, A. R.; O'Halloran, J.; Enviromental Toxicol. Chem. 1998, 17, 1429.

46. ABIA (Associação Brasileira das Industrias de Alimentação), 1991; Compêndio da Legislação de Alimentos. Atos do Ministério da Saúde. 